\title{
Comparative Analysis of Genetic Diversity Among Bacillus Thuringiensis and Bacillus Sphaericus and Their Fusants Using Molecular Markers
}

\author{
El-Kawokgy Tahany Mohamed Abou El-Fath ${ }^{1}$, Ibrahim Shafik Darwish ${ }^{2}$, Ashraf Gamil Attallah ${ }^{1}$ \\ ${ }^{1}$ Microbial Genetics Department, National Research Centre, Giza, Egypt \\ ${ }^{2}$ Molecular Genetics and Genome Mapping Department, Agricultural Genetic Engineering Research Institute (AGERI), Agricultural \\ Research Center (ARC), Giza, Egypt
}

Email address:

shafik732003@yahoo.com(I. S. Darwish),tkawokgy@hotmail.com(E. T. M. A. El-Fath), ashrafgamil2000@yahoo.com(A.G.Attallah), ashrafattallah@icloud.com(A.G.Attallah)

\section{To cite this article:}

El-Kawokgy Tahany Mohamed Abou El-Fath, Ibrahim Shafik Darwish, Ashraf Gamil Attallah. Comparative Analysis of Genetic Diversity Among Bacillus Thuringiensis and Bacillus Sphaericus and Their Fusants Using Molecular Markers. Biochemistry and Molecular Biology. Vol. 3, No. 5, 2018, pp. 63-70. doi: 10.11648/j.bmb.20180305.11

Received: November 10, 2018; Accepted: December 7, 2018; Published: January 10, 2019

\begin{abstract}
Ten genetically stable fusants strains were obtained as a result of protoplast fusion technique between Bacillus sphaericus (Bs) and Bacillus thuringiensis (Bt), six of them produced from, Bs GHAI Bt 66 Ia experiment (fusants no. 1, 2, 16, 26, 31 and 34) and four fusants produced from Bs GHAI Bt I977experiment (fusants no.1, 2, 17 and 25). Two molecular marker systems, four ISSR primers (Inter-Simple Sequence Repeat) and seven SCoT primers (Start Codon Targeted Polymorphism) were employed for detection of genetic variation between the parents and their fusants. Four ISSR primers and seven SCoT detected 55and 97 amplicons, among which $92.696 \%$ and $81.948 \%$ bands were polymorphic respectively. The genetic similarity values among the species were calculated based on ISSR and SCoT profiles which ranged from 0.50 to 0.83 and 0.59 to 0.90 respectively. Based on the marker analysis, the three parents and the ten fusants were clustered into three major groups for ISSR primer and SCoT primers. Cluster analysis were performed to construct a dendrogram of the Bacillus Strains and their fusants and also reveals high genetic variation among the parents and their fusants. It could be concluded that each type of the two molecular marker approaches of DNA analysis could identify the different between the parents, and all of their fusants under investigation have probably originated from closely related ancestors and possess high degree of genetic similarity.
\end{abstract}

Keywords: Bacillus Thuringiensis, Bacillus Sphaericus, Genetic Diversity, ISSR and SCoT Marker

\section{Introduction}

Molecular markers are mainly used in molecular biology and biotechnology to recognize a specific sequence of DNA in a pool of unknown DNA. It can be defined as a variation that could be detected. A genetic marker may be a long DNA sequence, or a short one [1]. They can recognize variation at the DNA level e.g., nucleotide changes, deletion, duplication, inversion and or insertion [2].

SCoT is a simple, new and gene targeted DNA marker depend on the short-conserved region in genes [3]. Primers for SCoT marker study were planned from the conserved region surrounding the translation initiation codon ATG [4].
SCoT markers are considered as more precise than RAPD and ISSR, and it is proposed that primer length and annealing temperature are not the only factors responsible for reproducibility [5]. This procedure includes formation of single primers from the short-conserved region adjoining the ATG start codon without knowing any information about the genomic sequence [3]. The value of this primer in analysis of genetic variation has been informed in a group of plant species [4].

Inter-Simple Sequence Repeats (ISSRs) are sites in the genome lined by microsatellite sequences. PCR amplification of these regions by using a single primer produce multiple amplification products that could be used as a dominant multi 
locus marker system in knowing the genetic variation in different organisms. ISSR markers are easy to use, with low cost, and with little demand in its method comparing to other dominant markers, making it a perfect genetic marker for beginners and for organisms with lacking genetic information [6].

The ISSR are semi arbitrary markers amplified by PCR in the presence of one primer complementary to a target microsatellite. Each band corresponds to a DNA sequence demarcated by two inverted microsatellites [7].

In genetic variation studies, a good genetic marker must have high genetic variability with the ability to generate multi locus data from the studied genome [8]. The production of ISSR markers, tack advantage of microsatellite sequences that are highly variable and universally distributed across the genome. So ISSR is a good genetic marker for various researches, on genetic variation or diversity [9], DNA fingerprinting [10], and phylogenetic [11].

The current study was conducted to determine the genetic similarity among the three parents Bt(66 Ia), Bt (I977) and Bs (GHAI) and their fusants using different marker systems and to compare the efficiency between SCoT and ISSRs for diversity analysis.

\section{Material and Methods}

\subsection{Bacterial Parental Strains}

Bacillus thuringiensis Bt 66 Ia (Bt); a UV resistant mutant of a local $B t$ strain isolated from dead snails collected from Giza Governorate, Egypt [12], Bt I 977 and Bacillus sphaericus (Bs) GHAI obtained from Microbial Genetics Department, National Research Centre, Cairo, Egypt.

\subsection{Fusants Strains}

Ten fusants stains; six of them produced from $B s$ GHAI: $B t$ 66 Ia experiment (fusants no. 1, 2, 16, 26, 31 and 34) [13] and four fusants produced from $B s$ GHAI $B t$ I 977experiment (fusants no. 1, 2, 17 and 25) [14]. All fusants strains induced 100 percent mortalities against $S$. litoralis larvae after seven days of feeding at all concentrations and to $C$. pipiens larvae after one day of feeding at all concentrations.

\subsection{DNA Extraction}

Total genomic DNA of all the studied strains was obtained by DNeasy Mini Kit (QIAGEN). The concentration of DNA was then determined based on a comparison of the DNA samples with standard lambda DNA on $1 \%(\mathrm{w} / \mathrm{v})$ agarose gel, after which it was adjusted to $5 \mathrm{ng} / \mu 1$. [15].

\subsection{Inter Simple Sequence Repeat (ISSR) Technique}

ISSR-PCR reactions were conducted using four anchored primers, which were synthesized by Eurofins, Germany. The primer names and primer sequences are shown in (Table 1). The reaction conditions were optimized and the following reagents were mixed in a final volume of $25 \mu \mathrm{l}$ : $1 \mathrm{X}$ of green
GoTaq Flexi buffer; $1.5 \mathrm{mM}$ of $\mathrm{MgCl}_{2} ; 200 \mu \mathrm{M}$ of dNTPs (Promega); 25pucM of primer; 1 U of GoTaq Flexi DNA Polymerase (Promega); 25ng of template DNA and up to 25 $\mu 1$ double distilled water. Amplification was carried out in a T100-Bio-Rad Gradient Thermal cycler. The following programmer was used to amplify the DNA: $94^{\circ} \mathrm{C} / 5 \mathrm{~min}(1$ cycle); $\left[94^{\circ} \mathrm{C} / 45 \mathrm{sec}, 45^{\circ} \mathrm{C} / 50 \mathrm{sec}, 72^{\circ} \mathrm{C} / 1.5 \mathrm{~min}\right](40$ cycles $)$; $72^{\circ} \mathrm{C} / 7 \mathrm{~min}(1 \mathrm{cycle})$ and $4^{\circ} \mathrm{C}$ (infinitive). A volume of $10 \mu 1$ of the ISSR-PCR product was resolved using $1.5 \%$ agarose gel electrophoresis containing ethidium bromide. A $100 \mathrm{bp}$ DNA marker (Fermentas) was used as a DNA molecular weight standard. Results were visualized on a UV transilluminator and photographed by Molecular Imager ${ }^{\circledR}$ Gel Doc ${ }^{\mathrm{TM}}$ System with Image Lab ${ }^{\mathrm{TM}}$ Software, Bio-Rad. Only the clearest and strongest ISSR bands were scored manually as present (1) or absent (0) to be used for further analysis.

Table 1. Primer name and primer sequence used in the ISSR analysis.

\begin{tabular}{ll}
\hline Primer name & Primer Sequence \\
\hline ISSR-3 & 5'-ACACACACACACACACYT-3' \\
ISSR-4 & 5'-ACACACACACACACACYG-3' \\
ISSR-8 & 5'-AGACAGACAGACAGACGC-3' \\
ISSR-18 & 5'-GTG TGT GTG TGT GTG TC-3' \\
\hline
\end{tabular}

\subsection{SCoT (Start Codon Targeted) Technique}

Seven SCoT primers were used in this study (Table 2). The reaction conditions were optimized and the following reagents were mixed in a final volume of $25 \mu \mathrm{l}$ containing $2 \mu \mathrm{L}$ of template DNA $(25 \mathrm{ng} / \mu \mathrm{L}) ; 2.5 \mu \mathrm{L}$ primer at 10 pucM; $0.5 \mu \mathrm{L}$ dNTPs at $10 \mathrm{mM} ; 0.15 \mu \mathrm{L}$ Taq DNA polymerase at $5 \mathrm{U} / \mu \mathrm{L} ; 5 \mu \mathrm{L} 5 \mathrm{X}$ PCR buffer; and $14.75 \mu \mathrm{L}$ double distilled water. SCoT-PCR amplification was carried out in a T100Bio-Rad Gradient Thermal cycler programmed as follows: initial denaturation was carried out at $94^{\circ} \mathrm{C}$ for $5 \mathrm{~min}$, followed by 35 cycles of $94^{\circ} \mathrm{C}$ for $1 \mathrm{~min}, 50^{\circ} \mathrm{C}$ for $1 \mathrm{~min}$, $72^{\circ} \mathrm{C}$ for $1.5 \mathrm{~min}$, and final extension at $72^{\circ} \mathrm{C}$ for $7 \mathrm{~min}$. The amplification products were separated in $1.5 \%$ agarose gels containing $0.5 \mu \mathrm{g} / \mathrm{mL}$ of ethidium bromide through electrophoresis in $1 \mathrm{X}$ TBE buffer solution at $5 \mathrm{~V} / \mathrm{cm}$ and photographed by Molecular Imager ${ }^{\circledR}$ Gel Doc ${ }^{\mathrm{TM}}$ System with Image Lab ${ }^{\text {TM }}$ Software, Bio-Rad.

Table 2. Primer name and primer sequence used in the SCoT analysis.

\begin{tabular}{ll}
\hline Primer Name & Primer Sequence \\
\hline SCoT-17 & CCATGGCTACCACTACCC \\
SCoT-25 & ACGACATGGCGACCGCGA \\
SCoT-26 & ACGACATGGCGACCACGT \\
SCoT-27 & ACCATGGCTACCACCGTC \\
SCoT-35 & AACCATGGCTACCACCAC \\
SCoT-36 & CACCATGGCTACCACCAT \\
SCoT-47 & ACCATGGCTACCACCGCG \\
\hline
\end{tabular}

\section{Results and Discussion}

ISSR- and SCoT PCR Analysis

In this study, two marker systems; ISSR and SCoT, were successfully used to differentiate between $B t$ and $B s$ parents 
and their ten fusants stains; six of them produced from $B s$ GHAI:: Bt 66 1a experiment (fusants no. 1, 2, 16, 26, 31 and 34) [13] and four fusants produced from Bs GHAI:: Bt I 977 experiment (fusants no.1, 2, 17 and 25) [14]. A total of 11 primers were used and 55 bands for ISSR and 97 bands for SCoT were produced, with a mean of 13.750 and 13.857 bands per primer, respectively, among which $92.696 \%$ and $81.948 \%$ were polymorphic for ISSR and SCoT, respectively. ISSR and SCoT markers were calculated in order to characterize the capacity of each primer to detect polymorphic loci among the parents and their fusants.

ISSR is a suitable molecular typing technique for the study of genetic diversity of a wide variety of organisms. Screening to obtain an efficient set of primers is very important when using ISSR typing $[16,15]$.

Using Eleven primers; four for ISSR, and seven for SCoT, which were selected previously based on the number of bands that they produced and the polymorphism of these bands.

\section{ISSR-Polymorphism}

The most polymorphic primers were ISSR-8 which produced 17 bands, followed by primer ISSR-18, primer ISSR-4 and primer ISSR-3 which produced 15, 12 and 11 bands, respectively (Table 3 ).

(Figure 1) shows PCR products of the four ISSR primers. Among the four-decamer oligonucleotide primers, primers varied greatly in their ability to resolve variability among $B t$ 66 Ia:: Bs GHAI and their fusants. Some primers produced several bands, while others produced a few bands.

ISSR-primers produced polymorphism ranged from 83.3 to $100 \%$. Primer ISSR-3 produced the highest percentage of polymorphism $(100 \%)$ and did not produce any monomorphic band, while primer ISSR-4 produced the lowest one(83.33) with two monomorphic bands. Mean of band frequency of each primer ranged from $0.380 \%$ to $0.500 \%$. ISSR-8, appeared high polymorphic bands within the isolates in our study, while the ISSR-4 primer gave the highest mean of band frequency $(0.500 \%)$ with $83.33 \%$ polymorphism efficiency. Our results showed that there is a high genetic variation among the parents and their fusants, that is in agreement with the results from previous studies carried out on Aspergillus flavus-strains [17]. Polymorphism of each primer was calculated as a percentage of polymorphic bands to the total number of bands produced by the designated primer [18].
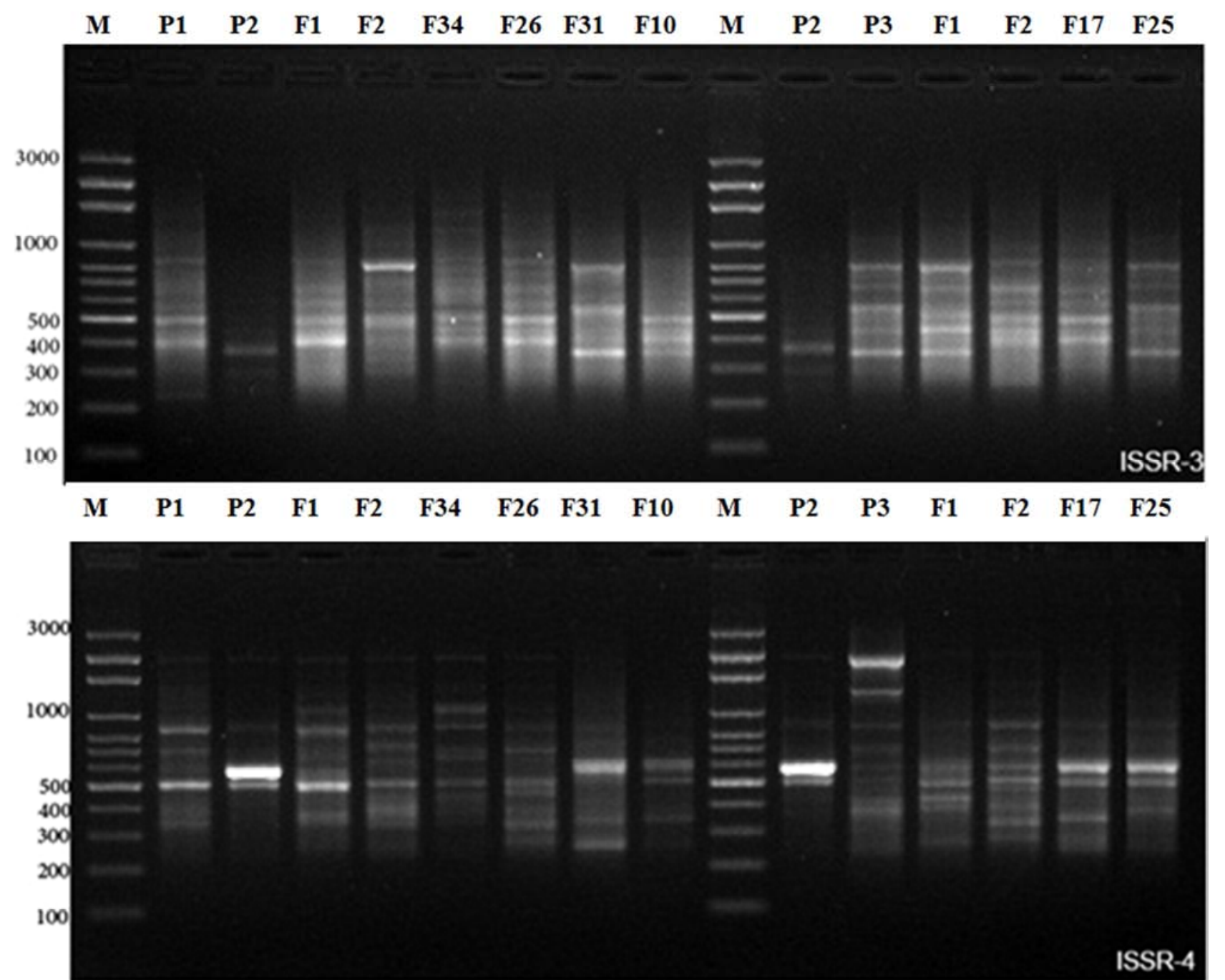

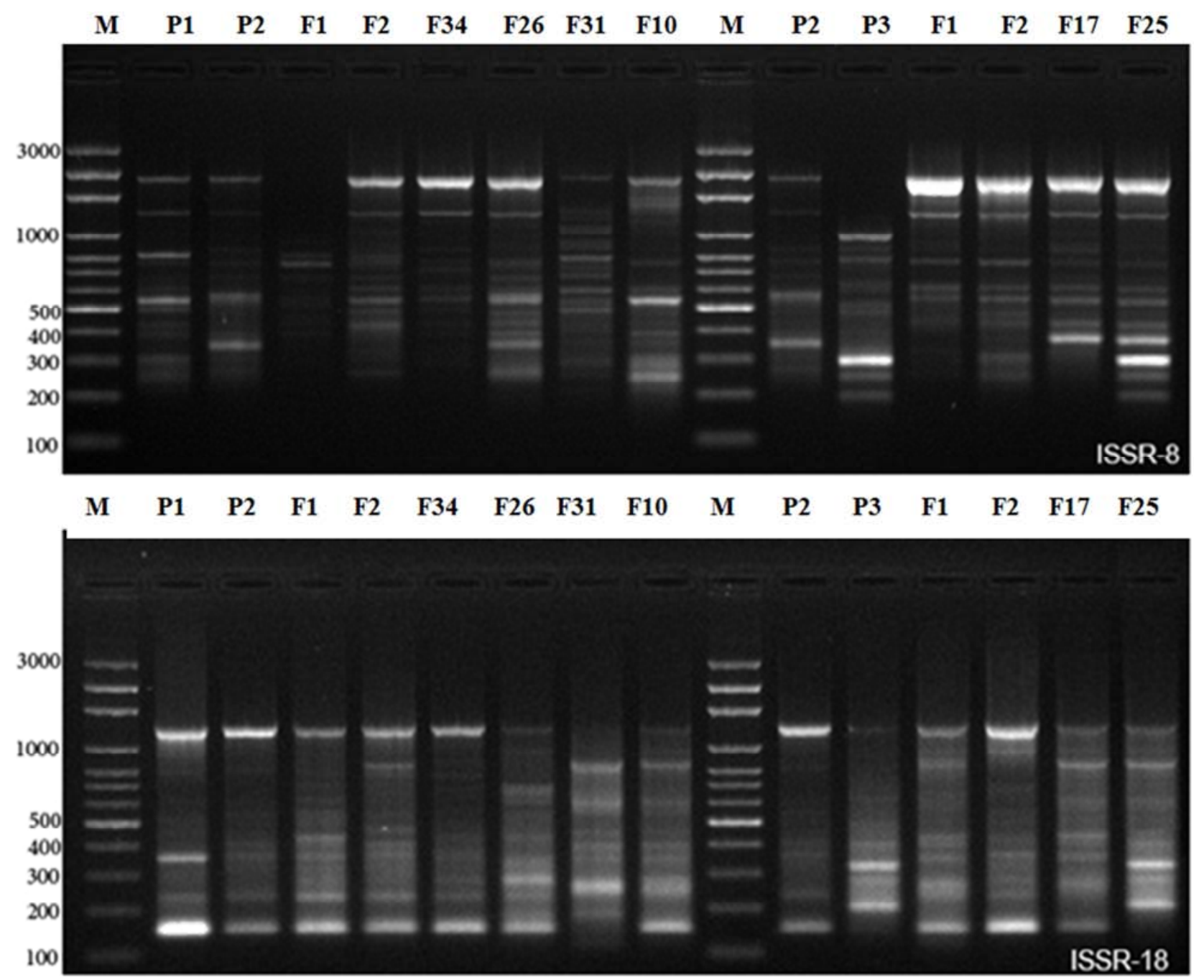

Figure 1. PCR products with ISSR marker profiles. Lanes 2\&3; P1(Bt 66 1a); P2( Bs GHAI) Lanes 4-9 are their fusants (1, 2, 16, 26, 31 and 34); Lane 11-12; P2( Bs GHAI); P3( Bt I 977) and Lanes 13-16 are their fusants (1, 2, 17 and 25); Lane (1\&10) M GeneRuler100bp plus DNA ladder.

Table 3. Statistical analysis of ISSR primers used in this study and the amplification results.

\begin{tabular}{llllllll}
\hline \multirow{2}{*}{$\begin{array}{l}\text { Primer } \\
\text { Name }\end{array}$} & ISSR Primers & \multicolumn{1}{l}{} & & & \\
\cline { 2 - 7 } & Primer Sequence 5'-3' & $\begin{array}{l}\text { No Of Scored } \\
\text { Bands (NSB) }\end{array}$ & $\begin{array}{l}\text { No Of Poly- } \\
\text { Morphic bands } \\
\text { (NPB) }\end{array}$ & $\begin{array}{l}\text { Polymorphism } \\
\text { (PPB)\% }\end{array}$ & $\begin{array}{l}\text { No Of } \\
\text { Monomorphic } \\
\text { Bands }\end{array}$ & $\begin{array}{l}\text { No Of } \\
\text { Unique } \\
\text { Bands }\end{array}$ & $\begin{array}{l}\text { Mean of } \\
\text { Band } \\
\text { Frequency }\end{array}$ \\
\hline ISSR-3 & 5'-ACACACACACACACACYT-3' & 11 & 11 & $100.000 \%$ & 0 & 0 & $0.479 \%$ \\
ISSR-4 & 5'-ACACACACACACACACYG-3' & 12 & 10 & $83.333 \%$ & 2 & 1 & $0.500 \%$ \\
ISSR-8 & 5'-AGACAGACAGACAGACGC-3' & 17 & 16 & $94.118 \%$ & 1 & 2 & $0.380 \%$ \\
ISSR-18 & 5'-GTG TGT GTG TGT GTG TC-3' & 15 & 14 & $93.333 \%$ & 1 & 1 & $0.444 \%$ \\
Total & & 55 & 51 & & 4 & 4 & $1.803 \%$ \\
Average & & 13.75 & 12.75 & $92.696 \%$ & 1 & 1 & $0.45 \%$ \\
\hline
\end{tabular}

A total of 55 bands were generated from four ISSR primers (Table 3), and all of them were polymorphic bands. The total bands per primer ranged from 11 (ISSR-3) to 17 (ISSR-8). The size of the amplified fragments had ranged from $184 \mathrm{bp}$ to 1,731 bp (Figure1).

There are many studies indicated that ISSR - PCR is depended on the sensitive reaction condition. Optimization of PCR condition is necessary to get the highest specificity and product yield [17, 19]. Optimization of PCR condition, including temperature, number of cycle, reagents and other parameters are very necessary to get successful ISSR-PCR reaction [20]. Variation in the number of bands amplified by different primers influenced by variable factors such as primer structure and the annealing sites in the genome [21, 22], so in the present study, we used four different primer structures for reveal the genetic diversity among the strains and we found high rate of variation between them, but the intensity of the bands was not taken into account because of the DNA concentration was not controlling exactly at $50 \mathrm{ng}$ for each sample, which means that the number of copies of DNA template was not the same for all sample that may 
affected the intensity of the resulted bands. In this study, the unique bands and the polymorphic bands were generated. Unique band means that the presence of band in a specific variety and absence of it with the same size in all other varieties [23, 24, 25] they suggested that the application of unique markers in DNA typing and variety identification.

\section{SCoT Polymorphism}

The marker system Start Codon Targeted Polymorphism that is based on the short conserved region in genes surrounding the ATG translation start (or initiation) codon that has been well characterized in previous studies [26, 27]. DNA markers are produced by polymerase chain reaction (PCR) using single primers that are designed from the short conserved region flanking the ATG start codon that is conserved for all genes. Therefore, in principle, this technique is similar to RAPD or ISSR or single primer amplification reaction because a single primer is used as the forward and the reverse primer $[19,28]$. Due to the basis of SCoT primer design, we expect SCoT markers to be distributed within gene regions that contain genes on both plus and minus DNA strands. It is also possible that pseudogenes and (genes within) transposable elements may be used as primer binding sites by SCoT polymorphism technique. An important factor is the distance in base pairs between primer binding sites of the template. Therefore, a relatively long extension time of the thermal cycle is important and we suggested at least $1-\mathrm{min}$. SCoT primers in this study were designed based on a consensus sequence for the flanking region around the ATG start codon derived from the previous studies [26, 29]. Most primers differed from each other by at least one nucleotide with an emphasis on variations at the $3^{\prime}$ end, which has been shown too critical for primer-template specificity [30, 31].

Primers sequences, code, number of scored bands (NSB), number of polymorphic bands (NPB) and percent of polymorphic bands (PPB)for SCoT primers are shown in (Table 4).

Polymorphism was observed for all primers used in this study. In addition, the total number of scored bands (97) and polymorphism was observed for 80 of them. SCoT-26 primer with 19 bands had the highest number of bands and SCoT-36 primer with 9 bands had the lowest number of bands. Bands pattern of all SCoT primers are shown in Figure.2. Average of polymorphism percent was $81.948 \%$, the lowest percent of polymorphism (66.667\%) produced by SCoT-36 primer and the highest percent of polymorphism $91.667 \%$ produced by SCOT-17 and SCT-47 primers. The average of mean of bands frequency for all primers was $0.481 \%$ and the highest value produced by SCoT-36 (0.622\%) while the lowest one produce by SCoT-17 $(0.278 \%)$ (Table 4$)$.

(Table 4) also, shows that the three primers; SCoT-25, SCoT-26 and SCoT-27 produced 16, 19 and 16 scored bands, respectively. Out of the 97 scoured bands of PCR products, 80 were polymorphic bands and 12 were unique bands. These are comparable to the number of markers typically generated by RAPD and ISSR techniques in rice $[32,33,34]$ and also in Agrobacterium [35].

Table 4. Statistical analysis of SCoT primers used in this study and the amplification results.

\begin{tabular}{lllllll}
\hline SCoT Primers & & & & \\
\hline $\begin{array}{l}\text { Primer } \\
\text { Name }\end{array}$ & Primer Sequence 5'-3, & $\begin{array}{l}\text { No Of Scored } \\
\text { Bands (NSB) }\end{array}$ & $\begin{array}{l}\text { No Of Poly- } \\
\text { morphic Bands } \\
\text { (NPB) }\end{array}$ & $\begin{array}{l}\text { Polymorphis } \\
\text { m (PPB)\% }\end{array}$ & $\begin{array}{l}\text { No Of Unique } \\
\text { Bands }\end{array}$ & $\begin{array}{l}\text { Mean of Band } \\
\text { Frequency }\end{array}$ \\
\hline SCoT-17 & CCATGGCTACCACTACCC & 12 & 11 & $91.667 \%$ & 3 & $0.278 \%$ \\
SCoT-25 & ACGACATGGCGACCGCGA & 16 & 12 & $75.000 \%$ & 2 & $0.500 \%$ \\
SCoT-26 & ACGACATGGCGACCACGT & 19 & 16 & $84.211 \%$ & 2 & $0.516 \%$ \\
SCoT-27 & ACCATGGCTACCACCGTC & 16 & 14 & $87.500 \%$ & 2 & $0.450 \%$ \\
SCoT-35 & AACCATGGCTACCACCAC & 13 & 10 & $76.923 \%$ & 1 & $0.518 \%$ \\
SCoT-36 & CACCATGGCTACCACCAT & 9 & 6 & $66.667 \%$ & 0 & $0.622 \%$ \\
SCoT-47 & ACCATGGCTACCACCGCG & 12 & 11 & $91.667 \%$ & 2 & $0.483 \%$ \\
Total & & 97 & 80 & & 81.948 & 1.714 \\
Average & & 13.8571 & 11.428 & & $3.367 \%$ \\
\hline
\end{tabular}
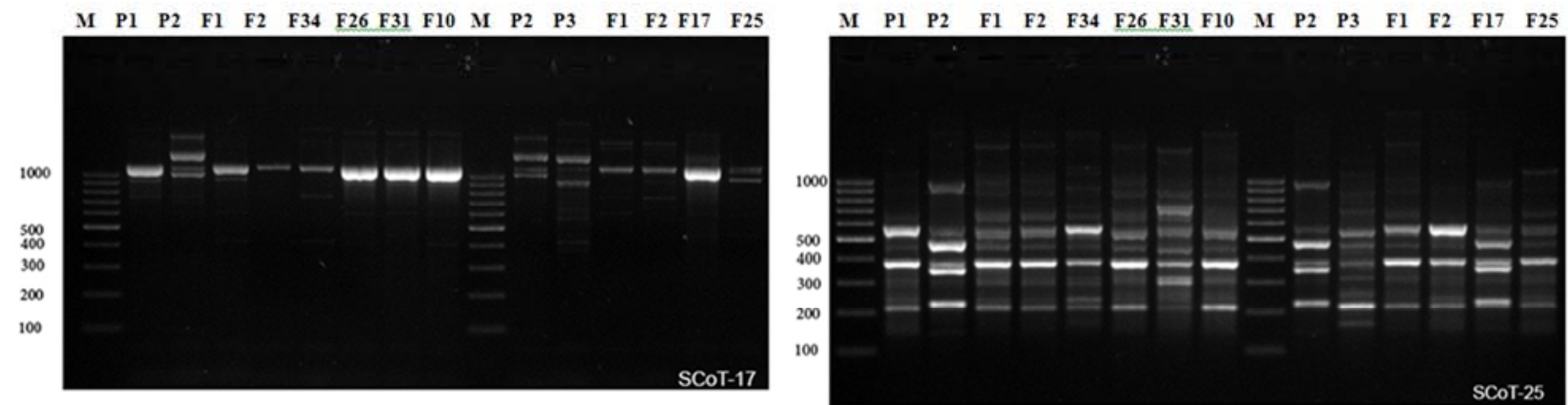

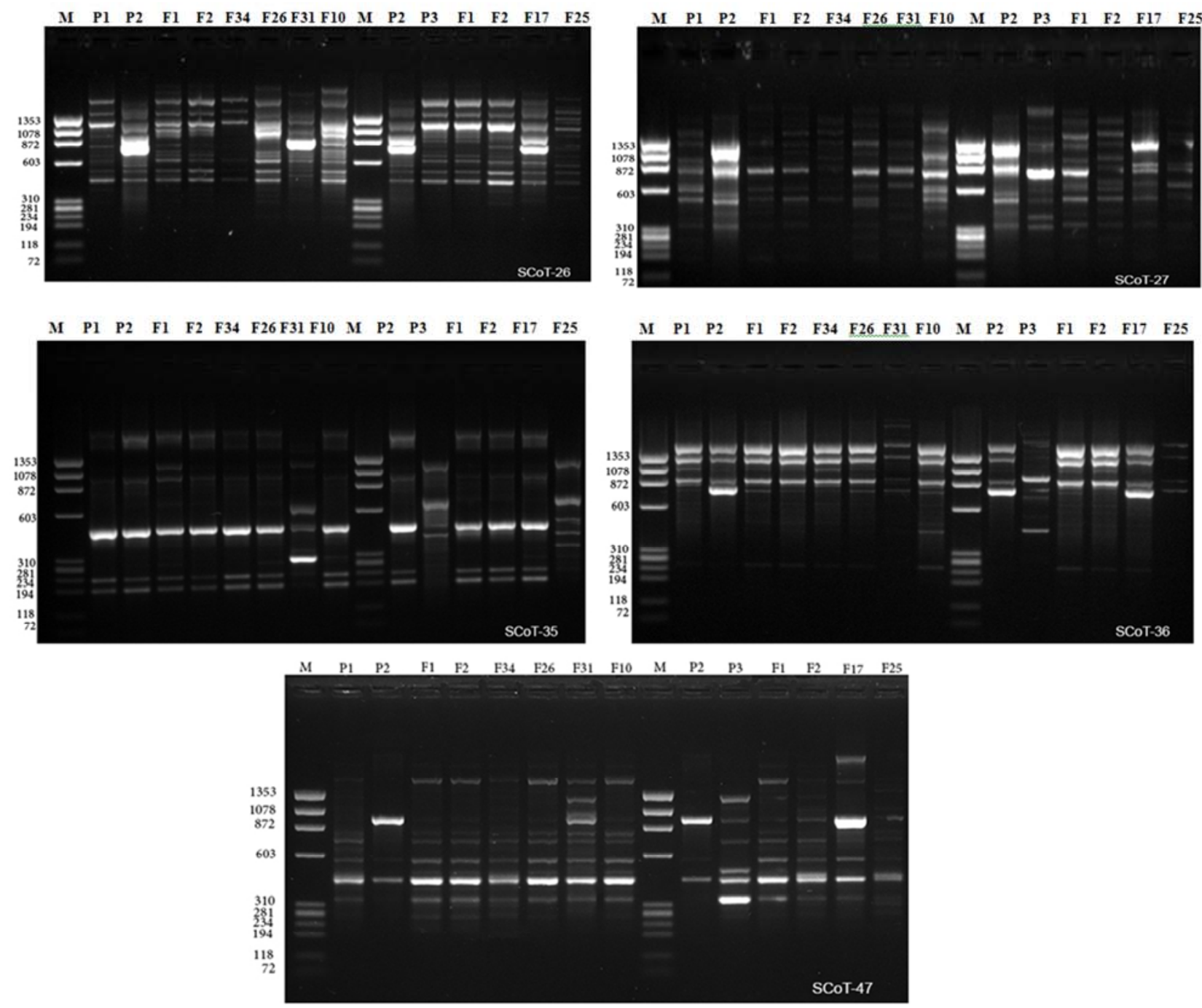

Figure 2. PCR products with SCoT marker profiles. Lanes 2\&3; P1(Bt 66 1a); P2( Bs GHAI) Lanes 4-9 are their fusants (1, 2, 16, 26, 31 and 34); Lanes 1112; P2( Bs GHAI); P3( Bt I 977) and Lanes 13-16 are their fusants (1, 2, 17 and 25); Lanes (1\&10) M GeneRuler100bp plus DNA ladder.

Cluster analysis with SPSS: Hierarchical Cluster Analysis

Cluster analysis works upwards to place every variable (strain) into a single cluster. The main part of the output from SPSS is the Dendrogram that represents the phylogenetic relationships among the variable (strains) under study. The Dendrogram for the ISSR and SCoT primers patterns of all strains using average linkage (between groups) is presented in (Figure 3).

In the present study, cluster analysis was done to estimate the level of polymorphism between the parental strains and their fusants. The genetic distances (GDs) among the three parents and their fusants ranged from 0.50 to 0.82 and 0.64 to 0.90 based on ISSR and Scot profiles, respectively. The dendrogram resulted from the banding patterns of ISSR and SCoT markers (Table 3\&4 and Figure 3). A dendrogram was constructed using a distance matrix by using the UPGMA method (Figure 3) depending on genetic distances from ISSR marker analysis showed that three major groups were observed. The fusants F16 and F1 were highly closely related and put in the first group (I) with similarity ranged from 0.66 to 0.73 , whereas F2, F2', F26, P1, F17, F34, F1' and F31were placed within the second group (II): (similarity ranged from 0.65 to 0.82 ). However, $\mathrm{P} 3$ and F25, which were put in the third group: (similarity range 0.63 to 0.65 ). On the other hand, the cluster analysis using UPGMA depending on genetic distances from SCOT marker analysis showed that the three parents and their ten fusants could be divided into three main groups (Figure 3-B). The first group (I) consisted of F17 and P2; (Bs GHAI). The second group (II) involved 2 sub-groups (similarity ranged from 0.78 to 0.90 ) consisted of F1, F2, F1', F2', F26, F34, P1(Bt I66/ Ia)and F16. The third group divided into 2 subgroups; F31 and F25; which closely related to $\mathrm{P} 3 ;(\mathrm{Bt}$ I977) (similarity ranged from 0.72 to 0.75 ). These results were in-agreement with those observed by [15] who reported that microsatellite markers were highly polymorphic and so useful for genetic analysis of Beauvaria sp. 


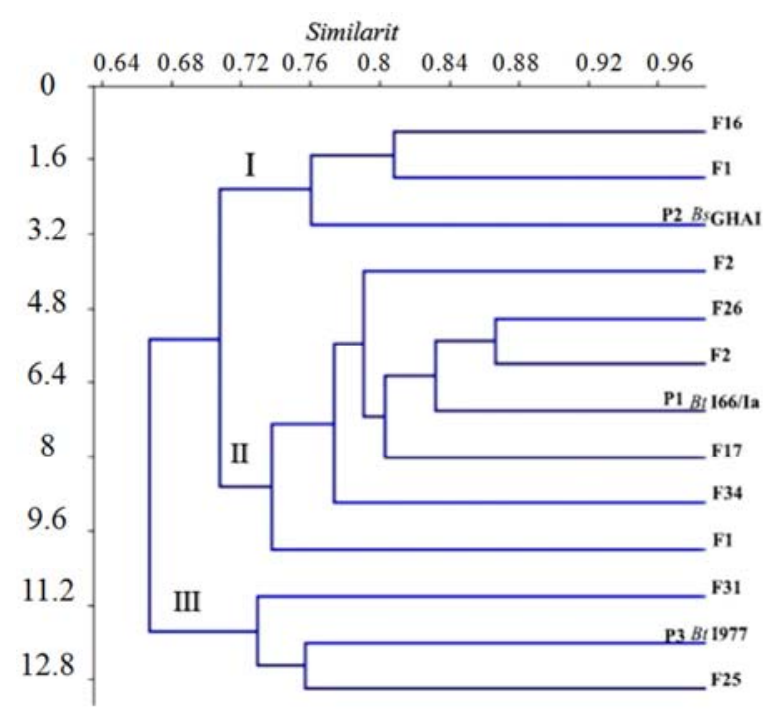

(A) Dendrogram ISSR data

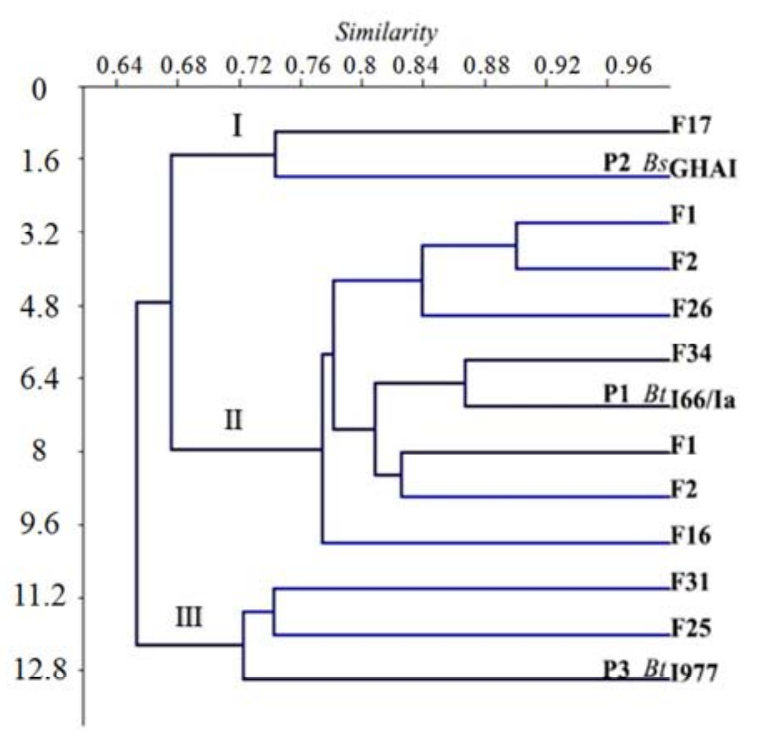

(B) Dendrogram SCoT data

Figure 3. Dendrogram illustrated genetic fingerprint and relationships between Bt and Bs strains and their fusants developed from ISSR (A) and SCoT (B)data.

P1:Bt 66 1a; P2: Bs GHAI and their fusants (F1, F2, F16, F26, F31 and F34); No: 1-6.

P2: Bs GHAI; P3: Bt I 977 and their fusants (F1', F2', F17 and F25); No: 7-10

\section{Conclusion}

In conclusion, this work has revealed that Comparative Analysis of Genetic Diversity Among Bacillus thuringiensis and Bacillus sphaericus and Their Fusants diversity exist with further experimentations, the ISSR and SCoT profile generated for each strains can be effectively used as a supporting marker for taxonomic identification and diversity.

\section{Acknowledgements}

The authors thank all members of Microbial Genetics Department, National Research Centre and also, at Molecular Genetics and Genome Mapping Department, Agricultural Genetic Engineering Research Institute (AGERI), Agricultural Research Center (ARC), Giza, Egypt

\section{References}

[1] Fraser, M. P., Yue, Z. W. and Buzcu, B. (2003). Source apportionment of fine particulate matter in Houston, TX, using organic molecular markers. Atmos. Environ. 37, $2117-$ 2123.

[2] Hibbett, D. S., Binder, M., Bischoff, J. F., Blackwell, M., Cannon, P. F., Eriksson, O. E., Huhndorf, S., James, T., Kirk, P. M., Lücking, R., et al. (2007). A higher-level phylogenetic classification of the Fungi. Mycol. Res. 111, 509-547.

[3] Zhang, Y., Yan, H., Jiang, X., Wang, X., Huang, L., Xu, B., Zhang, X. and Zhang, L. (2016). Genetic variation, population structure and linkage disequilibrium in Switchgrass with ISSR, SCoT and EST-SSR markers. Hereditas 153.
[4] Petrovičová, L., Balážová, Ž., Vivodík, M. and Gálová, Z. (2017). Detection genetic variability of secale cereale 1 . By scot markers. Potravinarstvo Slovak J. Food Sci. 11, 197-202.

[5] Gorji, A. M., Poczai, P., Polgar, Z. and Taller, J. (2011). Efficiency of Arbitrarily Amplified Dominant Markers (SCOT, ISSR and RAPD) for Diagnostic Fingerprinting in Tetraploid Potato. Am. J. Potato Res., Springer-Verlag 88, 226-237.

[6] Ng, W. L. and Tan, S. G. (2015). Inter-Simple Sequence Repeat (ISSR) markers: Are we doing it right? ASM Sci. J. 9, 30-39.

[7] Abdel-Mawgood, A. L. (2012). DNA Based Techniques for Studying Genetic Diversity. Genet. Divers. Microorg. 30.

[8] Anne, C. (2006). Choosing the right molecular genetic markers for studying biodiversity: from molecular evolution to practical aspects. Genetica, Kluwer Academic Publishers 127, 101-120.

[9] Shafiei-Astani, B., Ong, A. H. K., Valdiani, A., Tan, S. G., Yien, C. Y. S., Ahmady, F., Alitheen, N. B., Ng, W. L. and Kuar, T. (2015). Molecular genetic variation and structure of Southeast Asian crocodile (Tomistoma schlegelii): Comparative potentials of SSRs versus ISSRs. Gene 571, 107-116.

[10] Shen, J., Ding, X., Liu, D., Ding, G., He, J., Li, X., Tang, F. and Chu, B. (2006). Intersimple Sequence Repeats (ISSR) Molecular Fingerprinting Markers for Authenticating Populations of Dendrobium officinale. Biol. Pharm. Bull. 29, 420-422.

[11] Iruela, M., Rubio, J., Cubero, J. I., Gil, J. and Millán, T. (2002). Phylogenetic analysis in the genus Cicer and cultivated chickpea using RAPD and ISSR markers. Theor. Appl. Genet. 104, 643-651. 
[12] El-Kawokgy, T. M. A., Zowail, M. E. M. and Hegazy, W. K. (2004). Genetic improvement of Bacillus thuringiensis as a biocontrol agent against Biomphalaria alexandrina snail. Mansoura Univ. J. Agric. Sci. Egypt.

[13] El-Kawokgy, T. M. A., Hussein, H. A., Aly, N. A. H. and Mohamed, S. A. H. (2014). Highly toxic and broad-spectrum insecticidal local Bacillus strains engineered using protoplast fusion. Can. J. Microbiol. 61, 38-47.

[14] Hussein H. A, Kawokgy, T. A. M, Aly, N. A. H and Mohamed, S. A. H. (2014) Genetic modification of Bacillus Strains with a wide spectrum of insecticidal activities. J Genet Eng Biotechnol 8, 33-42.

[15] Attallah, A. G., Abo-Serreh, N. and Abd-El-Aal, S. K. (2014). Molecular Characterization of Beauvaria sp. with Inter Simple Sequence Repeat (ISSR) and RAPD Markers. Int. J. ChemTech Res. 6, 1407-1415.

[16] Ruas, P. M., Ruas, C. F., Rampim, L., Carvalho, V. P., Ruas, E. A. and Sera, T. (2003). Genetic relationship in Coffea species and parentage determination of interspecific hybrids using ISSR (Inter- Simple Sequence Repeat) markers. Genet. Mol. Biol. 26, 319-327.

[17] Hatti, A. D., Taware, S. D., Taware, A. S., Pangrikar, P. P., Chavan, A. M. and Mukadam, D. S. (2010). Genetic-diversityof-toxigenic-and-non-toxigenic-Aspergillus-flavus-strainsusing-ISSR-markers. African Journal of Biotechnology Vol. 2 (7), pp. 194-197.

[18] Ali, B. A. (2003). Genetics similarity among four breeds of sheep in Egypt detected by random amplified polymorphic DNA markers. Afr. J. Biotechnol. 2, 194-197.

[19] Williams, J. G. K., Kubelik, A. R., Livak, K. J., Rafalski, J. A. and Tingey, S. V. (1990). DNA polymorphisms amplified by arbitrary primers are useful as genetic markers. Nucleic Acids Res. 18, 6531-6535.

[20] Omear, H. A. (2009). Using The RAPD Markers To Analyze Variation Among Some Species Of The Genus Alternaria, PhD Thesis, MSc. thesis-Ccollage of Science-University of Tikrit. Iraq.

[21] Kernodle, SP, RE Cannon and JG Scandalios, Kernodle, SP, and RE Cannon and JG Scandalios. (1993). Concentration of primer and template qualitatively affects product in RAPDPCR. Biotechniques 1, 362-364.

[22] Abdulateef, S. M., Aljubori, M. H. and Abdulbaqi, N. J. (2014). Genetic Diversity Among Some Aspergillus flavus Isolates by Using Inter simple sequence repeats (ISSR). Iraqi J. Sci. 55,8 .
[23] Raghunathachari, P., Khanna, V. K., Singh, U. S. and Singh, N. K. (2000). RAPD analysis of genetic variability in Indian scented rice germplasm (Oryza sativa L.). Curr. Sci. 79, 994 998.

[24] Saker, M. M., Youssef, S. S., Abdallah, N. A., Bashandy, H. S. and Sharkawy, M. El. (2005). Genetic analysis of some Egyptian rice genotypes using RAPD, SSR and AFLP 9. African Journal of Biotechnology Vol. 4 (9), 882-890.

[25] Abdulateef, S. M., Aljubori, M. H. and Abdulbaqi, N. J. (2014). Genetic Diversity Among Some Aspergillus flavus Isolates by Using Inter simple sequence repeats (ISSR). Iraqi J. Sci. Vol 55, No.3A,:986-993.

[26] Sawant, S. V., Singh, P. K., Gupta, S. K., Madnala, R. and Tuli, R. (1999). Conserved nucleotide sequences in highly expressed genes in plants. J. Genet. 78, 123-131.

[27] Collard, B. C. Y. and Mackill, D. J. (2009). Start Codon Targeted (SCoT) Polymorphism: A Simple, Novel DNA Marker Technique for Generating Gene-Targeted Markers in Plants. Plant Mol. Biol. Report. 27, 86-93.

[28] Gupta, P. K., Varshney, R. K., Sharma, P. C. and Ramesh, B. (1999). Molecular markers and their applications in wheat breeding. Plant Breed. 118, 369-390.

[29] Joshi, A. K. and Schabes, Y. (1997). Tree-Adjoining Grammars. In Handbook of Formal Languages: Volume 3 Beyond Words (Rozenberg, G., and Salomaa, A., eds.), pp 69123, Springer Berlin Heidelberg, Berlin, Heidelberg.

[30] Sommer, R. and Tautz, D. (1989). Minimal homology requirements for PCR primers. Nucleic Acids Res. 17, 6749.

[31] Kwok, S., Kellogg, D. E., McKinney, N., Spasic, D., Goda, L., Levenson, C. and Sninsky, J. J. (1990). Effects of primertemplate mismatches on the polymerase chain reaction: Human immunodeficiency virus type 1 model studies. Nucleic Acids Res. 18, 999-1005.

[32] Ophel, K. and Kerr, A. (1990). Agrobacterium vitis sp. nov. for Strains of Agrobacterium biovar 3 from Grapevines. Int. J. Syst. Evol. Microbiol. 40, 236-241.

[33] Mackill, D. J. (1995). Classifying Japonica Rice Cultivars with RAPD Markers. Crop Sci. 35, 889-894.

[34] Kaushik, A., Saini, N., Jain, S., Rana, P., Singh, R. K. and Jain, R. K. (2003) Genetic analysis of a CSR10 (indica) $\times$ Taraori Basmati F3 population segregating for salt tolerance using ISSR markers. Euphytica 134, 231.

[35] EL-Shaer, H. F; Attallah, A. G; and AL-Namouly, Sh.D. (2014) Genetic Diversity Based on SCoT and ISSR Markers in Agrobacterium isolated from Egyptian 5, 1605-1616. 